\title{
Caste, social stigma and identity processes
}

\author{
Rusi Jaspal \\ Royal Holloway, University of London
}

\section{Citing this paper:}

Jaspal, R. (in press). Caste, social stigma and identity processes. Psychology and Developing Societies.

Rusi Jaspal, Department of Psychology, Royal Holloway, University of London, Egham Hill, Egham, Surrey TW20-0EX United Kingdom. Tel: 01784276323 Fax: 01784434347 E-mail: rusi.jaspal@gmail.com 


\title{
Caste, social stigma and identity processes
}

\author{
Rusi Jaspal \\ Royal Holloway, University of London
}

\begin{abstract}
Caste persists as an important socio-psychological phenomenon in many spheres of Indian social life and particularly within village contexts. It is argued that socio-psychological insights into caste identity and caste-based stigma may complement ongoing sociological and anthropological research into caste. Drawing upon identity process theory, this paper explores the possible functions performed by caste-based stigma both for the higher caste groups (HCG) and the 'Scheduled Caste' (SC) groups. It examines how the maintenance of the social hierarchy implicated in the caste system, the spatial and endogamous separation of caste groups and the historical division of labour in accordance with caste group affiliation may impinge upon identity processes among both groups. It is argued that caste group affiliation and caste-based stigma have differential and sometimes conflicting implications for identity processes among the $\mathrm{HCG}$ and SC. While negative social representations of the SC may threaten self-esteem among SC members, it may enhance the self-esteem, meaning and distinctiveness principles among the HCG. The systematic positioning of the caste ingroup and outgroups within the social matrix may enhance meaning and distinctiveness among both the HCG and SC. This paper highlights a potential rationale underlying caste group members' resistance to social change vis-à-vis caste, even among those who might be expected to benefit from such change. Some theoretical points are made in the form of testable hypotheses and methodological issues in caste-related research are considered.
\end{abstract}

Keywords: caste; identity; stigma; India; identity process theory; social psychology

Caste is a complex social and psychological construct. In attempting to define the concept, scholars most frequently invoke the importance of occupation, endogamy, social class and political power, although it remains unclear how these variables relate to one another and indeed which are prioritised by social actors themselves in everyday thinking vis-à-vis caste. Social hierarchy has featured prominently in scholarly explorations of caste, which prima facie seems appropriate given the emphasis upon social stratification and social restrictions regarding interactions between 'high' and 'low' castes. Gorringe and Rafanell (2007) highlight three key dimensions of caste, namely (i) social hierarchy, in which status is privileged over power and economic wealth; (ii) endogamous separation, whereby inter-marriage between castes and close social interaction are discouraged or forbidden; and (iii) an interdependent division of labour. Moreover, they claim that these dimensions function primarily at the level of collectives rather than individuals, since they refer to societal structures. However, in many urban and even rural settings within the Indian Subcontinent the interdependent division of labour, which is prioritised in their account of caste, may no longer apply, since social mobility is firmly under way, particularly within the sphere of employment. Moreover, this division of labour is non-existent in the South Asian Diaspora. It is noteworthy that there are multiple criteria of caste group comparison, which may be political, economic and educational. Nonetheless, caste persists as an important social and psychological phenomenon in various spheres of Indian social life and particularly within village contexts, in which it is said to constitute the primary institution governing personal and social relationships (Dumont, 1988; Gupta, 2004).

Although sociological and anthropological approaches are immensely useful in exploring the aforementioned dimensions of caste, caste is also a fundamentally psychological construct. Caste group members position themselves, psychologically, in relation to the caste system (consisting of their caste ingroup and caste outgroups). Moreover, it is likely that, in many cases, caste identity or caste group affiliation may serve particular psychological functions for the self- 
concept; in some cases, it may provide feelings of belongingness or self-esteem, for instance. In essence, caste groups are social identity categories and in self-identifying as members of these categories, individuals' social identities as caste group members become salient (Tajfel, 1981, 1982). Social identity approaches indicate that individuals may come to regard themselves as interchangeable exemplars of their social groups by viewing themselves and others primarily in terms of their caste group memberships (Turner et al., 1987). The phenomenological importance of caste as a social identity among many South Asians has led researchers working on the ethnography of other social identities (e.g. gender and ethnicity) to regard caste identity as a potentially important and influential variable (e.g. Gayer, 2000; Mand, 2006). The conceptualisation of caste as a social identity marks an important transition in social scientific research into caste; it enables researchers to explore the meanings and functions associated with caste group membership for the self-concept. Furthermore, it allows for important sociopsychological contributions to the field, which will undoubtedly enhance our understanding of this complex socio-psychological phenomenon.

Over the years, various different categories have been employed in relation to caste. The Scheduled Castes (SC) were previously referred to as the 'Untouchables', as they were widely considered to be 'impure'. The SC have possessed the lowest social status in the caste hierarchy and continue to be exposed to social stigma. Although caste-based discrimination (or casteism) is illegal in India, the social stigmatisation of the SC remains pervasive within society both in the Subcontinent and in the Indian Diaspora. 'Dalit' is the political term employed to refer to the $\mathrm{SC}$, which has facilitated a more positive self-construal among group members. The higher caste groups (HCG) include those groups which enjoy relatively high social status within the caste hierarchy; the present article focuses primarily upon the landowning Jats and priestly Brahmins, although other HCG are also considered. The Central Government of India refers to an intermediate category of Other Backward Castes, which are described as 'socially and educationally backward classes' (Gov. Of India, 2009). These caste groups are less socially and educationally advantaged than the HCG, but more advantaged than the SC. The list of groups included within this umbrella category is dynamic and may change in accordance with social, economic and educational factors. Given the dynamic nature of this umbrella category vis-à-vis the SC and HCG categories, which are relatively stable, the Other Backward Castes are not discussed in the present paper. However, it is possible that many of the theoretical ideas outlined in this paper will be applicable to groups included within the umbrella category.

It is acknowledged that categories such as SC and HCG are umbrella terms for social categorisation, but that they may not necessarily form primary categories for identity formation. Even within the SC umbrella category there exists a hierarchy of caste groups; for instance, the Valmikis are considered to be more socially disadvantaged than the Ravidasis. These specific caste groups are more likely to provide the basis for social identity formation. However, official use of the categories of SC and HCG at the institutional level render them meaningful units of analysis, since they now constitute social representations (see Philogène, 2000). Thus, while the Brahmin and Khatri caste groups, for instance, are qualitatively different (in terms of hierarchical position and group norms/ customs), they nonetheless form part of the umbrella category HCG. This constitutes a superordinate identity category (Gaertner \& Dovidio, 2000). This is also true of the Ravidasis and the Valmikis, for instance, both of which form part of the SC. A scholarly consideration of these umbrella categories permits the researcher to analyse relations between those who are now habitually categorised as SC members (e.g. Valmikis and Ravidasis) and those who are categorised as HCG members (e.g. Brahmins), regardless of the intra-category 
hierarchy. However, it is readily acknowledged that there exist intra-category differences, which are meaningful and worthy of scholarly analysis.

The primary aim of this paper is to explore, through the lens of identity process theory, the possible functions performed by caste-based stigma both for the HCG and the SC groups. While sociological accounts of caste have made important strides in identifying some of the core dimensions of caste identity, this paper explores how the maintenance of the social hierarchy implicated in the caste system, the spatial and endogamous separation of caste groups, and the historical division of labour in accordance with caste group affiliation may impinge upon identity processes among both the HCG and SC. Given the conceptual complexity of caste, the present paper does not seek to provide a comprehensive account of caste identity but rather it draws upon some of the existing sociological and anthropological literature in the field in order to develop some potentially generalisable hypotheses regarding caste, stigma and identity processes.

\section{Identity process theory}

It is clear that theoretical strands from social identity theory (Tajfel, 1982) are useful in understanding the psychological connection of the individual to their caste group and indeed how members of one caste group will interact with members of another. However, in order to explore the functions of caste identity and caste-based stigma for the self-concept, key predictions from identity process theory (IPT; Breakwell, 1986, 1992; Vignoles et al., 2006; Jaspal \& Cinnirella, in press) are of particular heuristic value. IPT suggests that identity resides in psychological processes, but that it is manifested through action, thought and affect. The individual is said to possess agency in constructing identity, although this process is subject to societal constraints such as dominant social representations functioning in particular social contexts. IPT identifies two processes involved in identity construction, namely (i) the assimilation-accommodation process, whereby new information (e.g. social representations, events) are absorbed into and accommodated within the identity structure; and (ii) the evaluation process, which continuously confers meaning and value upon the contents of identity. These processes are universal across all human beings.

The theory postulates that the two processes are guided by a variety of motivational principles, namely (i) continuity; (ii) distinctiveness; (iii) self-efficacy; (iv) self-esteem; (v) belonging; (vi) meaning; and (vii) psychological coherence. The continuity principle requires that the self remain the same over time despite imminent changes in one's social environment. More recently, it has been argued that the principle may motivate individuals to protect their ingroup from internal or external threats to its existence as a distinctive social entity (Jaspal \& Cinnirella, 2010b; Jaspal \& Yampolsky, in press). It is reasonable to assume that membership within a caste group enables individuals to perceive a historical connection with their ancestors, transcending generations, which would be expected to enhance feelings of temporal continuity (see also Jaspal \& Cinnirella, 2010a). The distinctiveness principle requires the perception that one (or one's ingroup) is unique, separate and positively distinctive from others (or outgroups) (Vignoles et al., 2000). For instance, individuals might engage in the process of social comparison, by comparing their caste ingroup with outgroups on dimensions which demonstrate the social 'superiority' of their ingroup (Turner, 1975). Self-efficacy refers to feelings of competence and control over one's life and future (Breakwell, 1992). Indeed, members of HCG may perceive greater control over their lives and social environment due to their privileged position within the social hierarchy. The self-esteem principle requires that individuals perceive personal or social worth. This principle is likely to be particularly pertinent to the domain of 
caste identity, since individuals may develop and maintain a positive self-conception on the basis of their membership in a HCG vis-à-vis members of SC (Gecas, 1982). The belonging principle refers to the need to maintain feelings of closeness to and acceptance from other people, which, like self-esteem, is likely to be particularly relevant in the context of the present paper, given that SC members have historically been marginalised by members of HCG due to the strict regulations regarding social interactions between caste groups (Gorringe \& Rafanell, 2007). The meaning principle refers to the need to find significance and purpose in one's life (Vignoles et al., 2006). Indeed, caste identity may allow caste group members to position themselves within the social matrix, which in turn will likely provide a sense of purpose in their existence therein. Finally, the psychological coherence principle refers to the motive to develop and maintain the subjective perception of compatibility and coherence between one's (interconnected) identities (see also Jaspal \& Cinnirella, in press). It has been found that some members of the SC have problematised the coherence of self-identifying/ being categorised as SC members and of identifying with mainstream Hinduism and Sikhism, which has led some SC groups to develop distinct religious identities (Kalsi, 1989; Puri, 2003; Dhanda, 2009). This may be attributed to the need for psychological coherence between inter-connected religious and caste identities.

IPT suggests that if the identity principles are, for whatever reason, obstructed, the processes will be unable to function satisfactorily, which will result in threats to identity. The individual will engage in creative coping strategies, functioning at the intrapsychic, interpersonal and intergroup levels, in order to restore and maintain appropriate levels of continuity etc. and to thereby reinstate the principled operation of identity processes (Breakwell, 1986). The present paper explores how caste identity and caste-based stigma may impinge upon the principled operation of identity processes and how individuals may respond to fluctuations within the identity structure. The substantive section of the paper begins with a consideration, through the interpretive lens of IPT, of the social stigmatisation of the SC and the implications for identity processes.

\section{Caste and social stigma}

The concept of stigma is vital in understanding how caste identity affects the lives of South Asians. Caste identity invariably involves the positioning of one's caste group within a social hierarchy; negative social representations of the SC evidence the stigmatisation of these groups, particularly among the HCG. Crocker, Major and Steele (1998, p. 504) highlight that 'a person who is stigmatized is a person whose social identity, or membership in some social category, calls into question his or her full humanity - the person is devalued, spoiled, or flawed in the eyes of others'. Accordingly, members of the SC are, in many cases, regarded with contempt by members of HCG due primarily to their membership in a 'devalued, spoiled or flawed' social category. Dovidio, Major and Crocker (2000) explain that stigma is inextricably linked to the value attributed to social identities, which suggests that the evaluation process of identity is most pertinently associated with the stigmatisation of SC (see Breakwell, 1986). Stigma consists of the recognition of difference based upon a negative distinguishing characteristic of one's social identity and the consequent devaluation and dehumanisation of the individual group member (Dovidio et al., 2000). This clearly demonstrates the perception of the individual as an interchangeable exemplar of the group with which they are associated by outgroup members (Turner et al., 1987). Caste group membership will likely 'provide the primary schema through which everything about them [caste group members] is understood' (Crocker et al., 1998, p. 507). It is reasonable to assume that the self-esteem principle of identity may be threatened by 
the perception that one's ingroup is stigmatised, given that this will not be conducive to the development and maintenance of a positive self-conception on the basis of one's social group membership (Breakwell, 1986; Jaspal \& Sitaridou, 2010). In short, collective caste identity has important consequences at the individual level, since the individual is considered primarily through the interpretive lens of their caste identity.

The salience of social representations of caste-based stigma is likely to depend upon social context. For instance, Crocker et al. (1998, p. 505) have argued that 'stigmatized individuals possess (or are believed to possess) some attribute, or characteristic, that conveys a social identity that is devalued in some particular social context'. However, here it is argued that, in many cases, caste identity constitutes a particularly salient identity category of psychological importance across a wide range of social contexts. This may be attributed to the significance of caste in a multitude of distinct social domains (Judge \& Bal, 2008). This is one of the unique characteristics of caste identity, which distinguishes it from other social identities such as gender, religious and national identities. More specifically, caste identity may override other social identities in a wide range of contexts, rendering it phenomenologically important for many South Asians. It is argued that stigmatising social representations are likely to become active among HCG members in thinking about and in participating in social interaction with members of SC.

Dovidio et al. (2000) are correct in highlighting the manifold consequences of stigmatisation; caste-based stigma can threaten psychological, social and even physical wellbeing among the stigmatised SC groups. Moreover, the present analysis considers the potential implications of caste-based stigmatisation for identity processes among the stigmatising HCG (see also Neuberg, Smith \& Asher, 2000). It is hoped that this will provide a more detailed account of the potential socio-psychological causes and consequences of caste-based stigma among both the stigmatising and stigmatised caste groups. The consequences of stigma for identity and well-being have frequently been considered in accordance with the 'type' of stigmatising condition held by the group or individual. Accordingly, researchers of stigma (e.g. Goffman, 1963; Jones et al., 1984; Dovidio et al., 2000) have commonly distinguished between the various 'dimensions' of stigmatising conditions, such as those physical stigmata which are readily visible (e.g. facial disfigurement) and those which may be more easily concealed (e.g. homosexuality). However, such criteria are likely to be inadequate for accounting for caste identity, since although there are no physical characteristics, which readily distinguish members of the stigmatised SC, it is relatively easy for individuals to ascertain one's caste group membership. This is facilitated by the spatial segregation of caste groups in many South Asian villages (Gorringe \& Rafanell, 2007), and the relative ease with which individuals enquire about each others' caste identities in the South Asian Diaspora (Ballard, 1994a). Thus, caste identity may be salient at the interpersonal level, despite its status as a fundamentally social rather than physical characteristic. In short, caste identity may in fact be equally as salient, socially and psychologically, as many of the physical stigmata described by researchers (Goffman, 1963; Dovidio et al., 2000).

\section{The construction of caste identity}

The centrality of stigma in the caste system is clearly epitomised in many scholarly accounts of caste. For instance, Ghurye (1969) highlights the following features of the caste system: (i) segmental division of society; (ii) social hierarchy; (iii) constraints upon social intercourse; (iv) civil and religious exclusionism and the concurrent privileging of HCG in these domains; and (v) 
restrictions in the domains of occupation and marriage. According to this account, society is divided into caste groups, which are allocated differential social status (positive or negative) in accordance with the group's position within the social hierarchy.

The socio-psychological process of categorisation is clearly an important prerequisite for the segmental division of caste groups. For instance, the Ravidasis (a SC) in Punjab are categorised by members of HCG as chamars (literally 'leatherworker'), while the Valmikis (a SC) are referred to by caste outgroup members as churhas (literally 'street sweepers'). These demeaning occupational titles serve to delineate caste groups in accordance with their historical social status and their historical position within the caste hierarchy. The maintenance of the caste hierarchy through the process of categorisation is likely to enhance the meaning principle of identity, since one is able to perceive social significance in one's caste group, particularly if the ascribed social position of one's group is positive. Moreover, it positions the caste ingroup in relation to outgroups, which in turn elucidates the social significance of outgroups. Incidentally, this social significance is perceived to be negative, which through processes of downward comparison may serve to elucidate the positivity of one's ingroup, thereby enhancing the selfesteem principle of identity (Wills, 1981). It is evident that stigma is implicated in this process of enhancing the self-esteem of one's ingroup, since these demeaning occupational titles clearly serve to emphasise the devalued and 'spoiled' category membership of the Ravidasis and the Valmikis.

The distinctiveness principle of identity motivates individuals to engage in the process of ingroup and outgroup categorisation, since this constructs the ingroup as distinctive from outgroups, providing individuals with an important sense of differentiation from others (Vignoles et al., 2000). Accordingly, caste groups will continue to be categorised in terms of their occupations, since this form of categorisation unambiguously positions them as 'other' to one's own caste group. This is inextricably related to the meaning principle of identity, since distinctiveness too safeguards the meaningfulness of one's identity (Codol, 1981). Given the agency of the individual (and the social group) in defining identity (Breakwell, 2010), it is hypothesised that when the principles of self-esteem, distinctiveness and meaning are jeopardised, caste-based categorisation will be employed in order to restore appropriate levels of these identity principles. Consequently, this may be regarded in terms of a coping strategy.

\section{Caste essentialism and stigma}

It has been observed that members of HCG tend to essentialise caste identity (Mahalingam, 2007). This enables them to stigmatise members of the SC regardless of the increased social mobility, which commonly characterises the SC experience particularly in urban areas of India and in the South Asian Diaspora. Nesbitt (1994) captures caste essentialism in her observation that even the Valmikis in the South Asian Diaspora remain victims of gross social disparagement despite their disidentification with the demeaning occupations traditionally associated with their group. Caste essentialism ensures that the SCs' disidentification with these stigmatised occupations has had little or no impact for their position within the social hierarchy. Consequently, the social representation of the Valmikis' perpetual association with the occupation of sweeping up debris in the village streets and of removing household waste from the homes of HCG members remains salient among members of HCG, despite their obvious abandonment of these occupations (Nesbitt, 1994). The perceived involvement of this essentialised group in 'polluting' occupations and activities renders the Valmikis a stigmatised group, which must be distanced from 'pure' groups in the minds of some HCG members. 
The potency of this social representation explains the continued discrimination against the Valmikis even in the South Asian Diaspora, where caste membership may be less conspicuous than in the Indian Subcontinent. In short, caste membership is essentialised and thus inescapable. The identity implications of the maintenance of this social representation merit scholarly attention. On the one hand, it is clear that the self-esteem principle is enhanced through processes of downward comparison with the SC, which ensures that social representations of their inferiority are encouraged and reproduced. On the other hand, it seems that members of HCG essentialise their caste identity, which perhaps necessitates the essentialisation of caste outgroups. Evidently, the psychological coherence principle requires the reconciliation of inter-connected social representations, which are internalised within the identity structure (Jaspal \& Yampolsky, in press). Thus, psychological coherence may be jeopardised by internalising the social representation that one's own caste identity is primordial and innate within the self-concept and the contradictory representation that outgroup caste identities are 'socially learnt' (cf. Mahalingam, 2007). It could be hypothesised that the extent to which individuals essentialise their own caste group will predict the extent to which they essentialise caste outgroups. Social representational symmetry in this way is likely to facilitate high levels of psychological coherence. This merits empirical attention since the socio-psychological consequences of caste essentialism may vary in accordance with the social status of specific caste groups. For instance, the consequences of essentialising one's own caste group membership may be positive for identity among high status caste groups, although, conversely, the essentialisation of caste identity may impede processes of social mobility among the SC (see also Mahalingam, 2007).

Mahalingam's (2007) psychological research into caste identity suggests that members of HCG are more likely to regard caste identity in essentialist terms, that is, as an identity acquired at birth. This could be attributed to the ensuing feelings of connectedness with previous generations of one's caste group, which will have positive implications for one's sense of group continuity. Conversely, members of the SC may reproduce the social representation that caste identity is socially constructed and acquired through social learning. It is interesting to draw comparisons with recent research into gay identity among British Muslim gay men (Jaspal \& Cinnirella, in press; Jaspal \& Cinnirella, 2010a), in which it was found that men who evaluated their gay identity in negative terms, as a stigmatised social identity, tended to perceive homosexuality as socially learnt and attributed its presence in their lives to the surrounding 'British culture'. Those individuals who accepted gay identity as a component of the selfconcept seemed to construct it in essentialist terms, as an identity acquired at birth. Parallels can be drawn with caste identity, since HCG may derive feelings of temporal continuity, positive distinctiveness and self-esteem from the essentialisation of their caste identity, while SC members may perceive scope for enhancing the self-efficacy principle through the possibility of social mobility afforded by the construal of caste identity in terms of a socially learnt identity.

The concept of caste essentialism may explain the stiff opposition of the HCG to the political attempts of the SC to attain equality with other caste groups. Jodhka (2004) exemplifies this in his analysis of the conflict between Jats and the SC in the government of a local temple in Talhan, Punjab. Similarly, Ram (2004) discusses the Ad-Dharm movement in the Punjab, which sought to create a distinctive collective politico-religious identity among members of the SC, independent of the Hindus, Sikhs and Muslims. The Ad-Dharm movement was curtailed by members of the HCG in its early stages, primarily through the strategy of denying members of the SC access to communal facilities and through other forms of intimidation (Pawar, 1993). 
Ram (2004) provides a detailed historical account of the specific ways in which the Ad-Dharm movement was impeded by members of HCG. It is likely that members of HCG sought to hinder the movement due to the perceived threats to the distinctiveness principle, which may be enhanced through the strict maintenance of caste boundaries. Caste essentialism implies that group boundaries are impermeable and that the social status attributed to groups is nonnegotiable, which provides impetus to the argument that caste distinctiveness must be protected. Although the Ad-Dharm movement was aimed at creating a new collective identity, its position within the hierarchical social structure was supposed to improve drastically as a result of the creation of this identity. Indeed, it is this blurring of the hierarchical boundaries, which could be said to pose threats to the positive distinctiveness of the HCG. Given the ubiquity of caste identity in Indian social life, in particular, this may constitute a major source of self-enhancement and self-esteem primarily through the positive distinctiveness of HCG from the SC. Thus, any attempt to dismantle the caste system through social mobility or the recategorisation of the SC in ways which obscure their historical stigmatisation are likely to be met with opposition from those caste groups which habitually rely upon the stigmatisation of the SC in order to ensure a sense of positive distinctiveness (Vignoles et al., 2000). Ram (2004, p. 347) notes that the Ad-Dharm movement has provided members of the SC with a new name and collective identity but that the 'blatant untouchability of the past has taken on a more subtle form'. In short, caste essentialism ensures that their social status has made little improvement at the interpersonal and intergroup levels, since other caste groups continue to regard SC as socially inferior, possibly as a means of maintaining and enhancing their positive distinctiveness from the SC. However, it is acknowledged that essentialism need not necessarily have these implications in all social contexts per se; for instance, essentialist versions of sexual categories have been employed in order to advocate systemic positive social change in parts of the Western world (Hegarty, 2002).

Despite attempts to improve the social status of the SC, there is some evidence that social representations of stigma associated with the SC have been internalised by members themselves, possibly due to the socio-structural constraints upon social mobility. Jeffrey (2001) highlights this in his analysis of a violent confrontation between a Jat landowner (HCG) and a SC labourer, which culminated in the Sub-Divisional Magistrate (also a member of the SC) advising the SC activists to apologise to the Jats regardless of culpability. Given the economic reliance of the SC upon the landowning Jats, it was deemed essential, in practical terms, for the SC members to apologise to the Jats in order to safeguard their socio-economic well-being. The root of this may be attributed to the internalisation of the social representation that the caste ingroup is perpetually stigmatised and that members of HCG will be unwilling to enter into negotiations with or to apologise to members of the stigmatised SC. In many ways, this illustrates a passive acceptance of the stigma associated with the SC, even at the highest bureaucratic levels, due to the hegemony of the social representation, its shaping of social structures and processes, and, consequently, its internalisation within the minds of individuals (Breakwell, 2001). However, it is acknowledged that caste-based stigma may be resisted by $\mathrm{SC}$ members in some social domains, such as in politics. Indeed, the SC enjoy high political capital as exemplified by the widespread support of the Samajwadi Party in India (Pai, 2000).

\section{Outgroup discrimination and self-esteem}

In understanding the stigmatisation of the SC, the concept of 'dominant castes' is of particular heuristic value. According to Srinivas (2002, p. 75), a caste group may be regarded as 
'dominant' when it 'wields economic and political power', constitutes a demographic majority, and when it enjoys a 'high' position within the social hierarchy. Indeed, socio-psychological accounts of group vitality highlight the interdependence of the variables of social status, institutional control and demographic superiority, all of which are implicated in the aforementioned concept of 'dominant castes' (see Giles, Bourhis \& Taylor, 1977; Bourhis et al., 1981). It seems that in order for the dominant castes to maintain their high social status vis-à-vis the SC, the latter are stigmatised and thereby constructed as socially inferior and inherently impure. The positive sense of self-esteem which is systematically derived from the high social status associated with one's ingroup helps to maintain and to enhance the principled operation of identity processes (Breakwell, 1986; Jaspal \& Sitaridou, 2010). Crucially, the maintenance of high social status may be contingent upon downward comparison and outgroup derogation, since the comparison of one's caste group to less 'fortunate' caste outgroups may increase one's selfworth (Wills, 1981). Indeed, this thesis is reflected in the social identity theory literature (Tajfel \& Turner, 1986; Brown, 2000; Hogg, 2000). The systematic stigmatisation of the SC safeguards the dominant position of the HCG vis-à-vis other caste groups, with positive outcomes for identity among the HCG. Moreover, the meaning principle is likely to benefit from the hierarchical organisation of one's ingroup vis-à-vis outgroups; this facilitates the perception of significance in the position of one's ingroup and of relative outgroups within the social matrix. This in turn renders group differences and differences in social status psychologically meaningful (Baumeister, 1991).

Given that some caste groups are conventionally associated with demeaning occupations such as the removal of dead cattle and tanning their hides for the production of leather, in the case of the Ravidasis, and sweeping up debris in the streets and removing waste from households, in the case of the Valmikis, these groups have been pervasively regarded by HCG as 'acchut' or 'untouchable' (Nesbitt, 1994). This is attributed largely to the perceived impurity of these groups due to their ascribed occupational roles within Indian society. However, despite the positive social change which has been achieved in Indian urban society, resulting in the SCs' rapid social mobility, caste-based segregation remains potent in most spheres of social life in rural Punjab. Indeed, caste boundaries are said to be keenly maintained and reproduced by members of both HCG and SC alike (Jodhka, 2002). This is observable even among SC members, many of whom themselves internalise and reproduce social representations of their caste ingroup's inferiority. It has been noted in ethnographic fieldwork that in social interactions with HCG members, SC members may assume a hunched posture, remove their towel from their shoulders and tie it around the waist, and raise one or both hands in greeting, symbolising their alleged social inferiority (Gorringe \& Rafanell, 2007). Moreover, there is a tendency to exhibit respect through specific forms of body positioning and through discernible physical distance from members of HCG. SC members are said to refrain from entering the houses of HCG members and instead tend to call out to the householder through the rear door. It is reasonable to assume the SCs' observance of these norms will benefit distinctiveness and self-esteem among the HCG, since they implicitly symbolise their relatively higher social status vis-à-vis the SC.

Given the pervasiveness of such patterns of behavioural interaction across time, it is likely that the SCs' uncritical reproduction of these patterns constitutes a means of safeguarding the continuity principle of their identity (Breakwell, 1986). This hypothesis is consistent with the assertion that social representations of ingroup inferiority are internalised by many SC individuals, since information which coheres with individuals' existing self-conceptions is readily recalled and reproduced (see Shrauger, 1975). This maintenance of the status quo may 
ensure that the continuity principle of identity remains intact (Breakwell, 1986). Although continuity does not preclude change per se, it is likely that massive social change, such as the restructuring of the caste system, which pervasively affects numerous dimensions of everyday life, may result in threats to continuity. Despite the potential for enhancing self-esteem through the abandonment of these intergroup norms, they continue to be observed by many SC members. This echoes the finding that the self-esteem principle is not a superordinate principle, which takes precedence over others (Vignoles et al., 2002). In some social domains, SC members seem to have internalised social representations of their inferiority and subordinate status vis-à-vis the HCG, which resultantly form part of their self-conception. Thus, it is the continuity principle which may govern their keen observance of the norms regarding social interactions with HCG.

Gorringe and Rafanell (2007) argue that caste-based patterns of social behaviour are consensually accepted by members of both HCG and SC groups since 'they are lived and performed on a daily basis' (p. 108). Thus, they come to form part of all caste groups' lived social 'reality'. This seems a plausible suggestion, since specific processes of everyday social interaction are likely to reinforce the social hierarchy. Social representations of SCs' inferiority are anchored to representations of their historical involvement in demeaning and 'impure' occupations, particularly in the minds of HCG members (see Moscovici, 1988). Despite social mobility among many members of the $\mathrm{SC}$, which has resulted in their subjective disidentification with the degrading occupations conventionally associated with their ingroups, 'the Untouchable body is deemed to be [impure] due to its contact with pollution in the form of animal carcasses and products, human waste and corpses' (Gorringe \& Rafanell, 2007, p. 104). Indeed, 'hygiene reasons' may be invoked by members of HCG when refusing to share cooking utensils with members of SC, regardless of their abandonment of 'impure' occupations. Thus, it seems that historical social representations are activated by individuals possibly in order to justify the alleged social inferiority of SC members and to essentialise them as perpetual occupants of these threatening social positions.

Indeed, justifications are necessary in order to dispel potential allegations of prejudice, which may threaten self-esteem given the increasingly negative social representations of castebased prejudice in many sections of Indian society (The Times of India, 2010). Moreover, human beings tend to regard themselves as fair and unprejudiced. The continuity principle requires the maintenance of this (positive) self-conception. Thus, some justification is inevitably required in order to maintain a system, which unambiguously discriminates against individuals due to an ascribed group membership. Arun (2007) argues that the SCs' perpetual association with dead cattle, evil spirits and the death of humans defines their low status vis-à-vis other caste groups and thereby legitimises their physical and social exclusion. Identity process theory enables the researcher to explain why and to predict the circumstances under which HCG members will maintain social representations of SC impurity, and justify their social and physical distance from the SC. While continuity and self-esteem are enhanced through the avoidance of allegations of prejudice, it is likely that the anchoring of social representations of the SC to representations of their involvement in impure activities serves to maintain continuity of selfdefinition as an inherently superior social group. Crucially, continuity is important in this instance since it involves an intergroup comparison which favours the caste ingroup through processes of downward comparison with obvious benefits for the self-esteem principle of identity (Wills, 1981; Breakwell, 1986). 


\section{Social exclusion and the belonging principle}

Given the stigma pervasively attached to SC, there are strict constraints on the nature of social interactions among SC and HCG, which extends to the use of communal spaces, such as places of worship. Indeed, Nesbitt (1994) discusses the social stigmatisation of Valmikis in Sikh temples frequented by members of HCG such as the Jats, which has led some Valmiki communities to establish their own temples. The stigmatisation of Valmikis has been communicated through the HCG members' refusal to share cooking utensils and crockery with Valmikis and through their attempts to prevent Valmikis from frequenting the kitchen areas and from distributing karah prashad (a sweet doughy mixture distributed to the Sikh congregation) due to their perceived 'impurity'. Moreover, Nesbitt (1994) alludes to the social representation among some members of HCG that 'Valmikis should not read, or even touch, the sacred scriptures because of their allegedly innate impurity' (Nesbitt, 1994, p. 119). Clearly, this potent and persistent social representation is grounded within the caste politics of the Indian village contexts, which indicates the relevance of the continuity principle. Jodhka (2004) notes that the $\mathrm{SC}$ are frequently asked to eat langar (the meal distributed to the congregation) after the HCG have left or to queue separately from the HCG in order to avoid contact between them. Moreover, the SC are rarely, if ever, permitted to participate in the preparation of langar due to the continual stigmatisation of the groups. The abandonment of caste-based segregation may be construed as a potential threat to the continuity principle, since it entails social change which may be inconsistent with one's self-conception and with the collective construal of the established social matrix. Consequently, it is hypothesised that, even in the South Asian Diaspora, the notion that caste-based segregation in places of worship and in dining may be abandoned will likely pose threats to the continuity principle of identity (Breakwell, 1986).

The problematisation of Valmikis' physical and spiritual contact with Sikh holy scripture performs a clear ideological function; it serves to construct Valmikis as socially inferior to other caste groups by denying them access to a superordinate religious identity. Although caste groups may be high or low in terms of social status, they may plausibly lay claim to a common religious identity (i.e. as Hindus, Sikhs etc). However, the exclusion of Valmikis calls into question their claim to a common religious identity. The SC are unambiguously constructed as unworthy of the superordinate Sikh religious identity (cf. Gaertner \& Dovidio, 2000). This is expected to be problematic for the belonging principle of identity among the 'otherised' members of the SC. The belonging principle requires feelings of closeness to and acceptance from relevant others within one's social ingroup (Baumeister \& Leary, 1995). It is easy to see that this places the SC within a particularly threatening social position, since their participation in communal religious spaces (i.e. the Sikh temple) implies self-definition as religious ingroup members with the perceived right to participate in these spaces. Consequently, one's 'otherisation' from communal spaces is likely to impede feelings of acceptance and inclusion, which may habitually be taken for granted, resulting in threats to the belonging principle. It must be reiterated that belonging is threatened in this particular context due to their perceived right to participate in religious institutions; where one's expected belonging to a group or institution is problematised, the belonging principle may be thought of as threatened.

The exclusion of SC members from religious social contexts is most conspicuously evidenced in Jodha's (2004) account of the landowning Jats' ostracisation of the SC in the Punjabi village of Talhan. In Talhan sixty to seventy per cent of the local population belongs to the SC while only twenty five per cent of the population consists of Jats (a HCG). His case study demonstrates the perceived implausibility of the SCs' participation in the government of 
religious shrines due to social representations of their innate inferiority to other castes. The SCs' contestation of the Jats' hegemony in the managing committee of the shrine was met with fierce opposition; Jodhka (2004) highlights that the SC were further ostracised through social and economic 'boycotting'. On the one hand, this demonstrates the unambiguous desire of the HCG to maintain the status quo, possibly in order to maintain and enhance the continuity principle of identity. Continuity may be jeopardised by social change, which is perceived as favouring outgroups and as jeopardising the socio-psychological well-being of the ingroup. The threat occurs when the prospect of such social change must be assimilated and accommodated within the identity structure (Breakwell, 1986). Historically, the landowning HCG have held hegemonic social status in the village and, thus, the admission of a power-sharing arrangement may be construed as an undesirable addition to the identity structure. This could be attributed to the ensuing inability of HCG members to provide a satisfactory 'theory' explaining and rationalising the participation of the $\mathrm{SC}$, who are pervasively regarded as being inherently inferior and, thus, incapable of performing the task at hand. On the other hand, the self-efficacy of SC members could be threatened by the potential feelings of disenfranchisement from a social institution to which they too lay claim, namely religion. Feelings of 'competence and control' may be impeded within religious contexts which are regarded as being at least partly associated with the caste ingroup (Breakwell, 1993, p. 205). Ultimately, it was ruled that there should be two committee members representing the SC, in addition to the ten Jat committee members. Jodhka (2004) demonstrates that, despite the nominal representation of the SC on the management committee, the legitimacy of the SC committee members is generally not recognised by the Jats, which resulted in a power imbalance. In this case, in particular, it is reasonable to regard the identity principles of the Jats and the SC as being vulnerable to threats, nonetheless. The Jats regard even the nominal inclusion of the SC as a symbolic threat to continuity and the nominal inclusion of the SC does little, in practical terms, to alleviate threats to self-efficacy.

\section{Segregation and the distinctiveness principle}

The Jats' exclusion of the SC from religious contexts may be regarded as one aspect of the existing caste-based segregation in many other social arenas of village life. Sharma (2003) has demonstrated in his work on caste that the spatial organisation of many Indian villages coheres with caste, which maintains the segregation of the stigmatised SC and the HCG. Spatial segregation indirectly ensures that social representations of the SC remain negative, since they encourage separation on the basis of the SCs' alleged impurity. Despite the Indian government's efforts to facilitate the integration of the SC into Indian society primarily through the coeducation of HCG children and those of the SC, segregation tends to persist. For instance, it has been observed that, increasingly, children of HCG are sent by their parents to private schools, which has resulted in a majority of SC children at state schools (Jodhka, 2004). It is noteworthy that most SC members do not have access to private education due to their traditionally underprivileged backgrounds, which means that private education has become the almost exclusive domain of the HCG. The negative social representations of state schools are apparent in the widespread reference to these schools as 'dalit' or 'harijan' schools. In short, they are associated specifically with the SC in the minds of the HCG members.

Identity processes may govern the apparent tendency for the HCG to maintain segregation. While the Indian government attempts to blur boundaries between the caste groups through collective education, HCG seek to maintain and enhance group distinctiveness, firstly, 
by categorising state schools as 'dalit' schools and thereby constructing them as inferior and, secondly, by appropriating private schools as their own. It is clear that through spatial and social segregation distinctiveness is achieved through the diverse range of sources identified by IPT researchers (Vignoles et al., 2000). Difference is maintained since intrinsic value-laden social representations of caste groups are encouraged and reproduced in order to justify segregation; separateness is reinforced through the act of spatially segregating the ingroup from the stigmatised outgroups; and position within the caste hierarchy is safeguarded through the association of the ingroup with advanced private education and the SC with poor state-funded education. Crucially, this suggests that the societal attempts to desegregate social contexts such as the Indian villages will likely be resisted by members of HCG, since the distinctiveness principle of identity may be regarded as being imperilled by the loss of difference, separateness and position, all of which seem to provide individuals with a positive sense of identity (Vignoles et al., 2000). This is a potentially problematic situation, since HCG members, in particular, seek to maintain their sense of caste distinctiveness, while the Indian government endeavours to dismantle caste boundaries. This reflects one discrepancy between the institutional and the social levels.

A related matter concerns inter-caste marriage, which may be regarded as an additional means of 'desegregating', both spatially and socially, the HCG and SC groups. Ghurye (1969) makes an accurate observation regarding the social restrictions regarding intermarriage between the SC and the HCG. Indeed, intermarriage tends to be highly stigmatised due to the general unwillingness of HCG members to accept within their social circles members of SC, who are largely perceived as being impure and inferior (Ballard, 1994c; Nesbitt, 1994). Judge and Ball (2008) observed that $70 \%$ of their respondents in urban areas of India perceived caste endogamy as an important means of preserving tradition, facilitating 'better understanding' within couples and 'family support', while $97 \%$ of their respondents in rural areas held the same social representations. These data suggest that Ghurye's (1969) observation regarding intermarriage remains a valid one; caste endogamy remains the social desideratum and, conversely, intermarriage between SC group members and HCG members is said to bring shame upon the family of the latter (Mahalingam, 2007). Given the importance of 'face' and honour in Indian society, it is likely that inter-caste marriage may jeopardise the self-esteem of HCG who perceive inter-caste marriage as a shameful dishonour, since this may impede the development and maintenance of a positive self-conception (Gecas, 1982).

Among the SC, the belonging principle of identity is unlikely to be jeopardised by the social representation that their caste ingroup is forbidden to marry HCG, given that inter-caste marriage has never been acceptable in Indian village contexts (Judge \& Bal, 2008). In fact, caste endogamy remains keenly accepted and encouraged even by the $\mathrm{SC}$, which indicates that there has not necessarily existed an expectation among the SC that intermarriage should be permissible. This reiterates the aforementioned point that only those contexts, in which individuals feel that they possess the right to be accepted and included, will affect the belonging principle of identity. However, this is not to be conflated with restrictions on collective participation in religious institutions (e.g. temples), which, conversely, are likely to pose threats to the belonging principle. Indeed, SC members generally do perceive themselves as possessing the right to partake in these social institutions.

Chowdhry (2004) identifies difference and hierarchy as two key characteristics of the caste system and suggests that strict endogamy constitutes a means of preserving difference and hierarchy. Given the importance of the distinctiveness principle in identity construction, the 
rejection and stigmatisation of those individuals who appear to transgress the caste system by engaging in inter-caste marriage may constitute a means of protecting the principle by discouraging other ingroup members from following suit. The desire for members of HCG to preserve the 'purity' of their caste groups and of group members seems to underlie the widespread acceptance and reproduction of the social representation that endogamy is crucial. This suggests that the maintenance of caste identity, provided that one's caste is evaluated in positive terms, may provide individuals with both distinctiveness and self-esteem, both of which are essential for positive identity construction. Inter-caste marriage may be regarded as jeopardising these principles, in particular. More specifically, since caste identity is pervasively essentialised and, thus, regarded as an identity inherited at birth, inter-caste marriages will likely be perceived by members of HCG as 'polluting' the purity of their ingroups and thereby jeopardising the self-esteem and continuity principles of identity (Dube, 2001; Mahalingam, 2007). The absence of a clearly defined 'Significant Other', with whom HCG may compare their groups favourably through the process of downward comparison, would be expected to threaten the self-esteem principle. Moreover, this would likely threaten the continuity principle of identity among the HCG, since the historical and temporally pervasive positivity and 'purity' of one's caste ingroup may be regarded as being imperilled.

Many scholarly accounts of caste in India suggest that the SC members generally seek social mobility, which is reflected in the improved political capital of the SC, for instance. Thus, it is interesting that even members of the SC in both urban and rural areas tend to reproduce the social representation that caste endogamy is crucially important, which indirectly contributes to the maintenance of caste-based segregation (Judge and Ball, 2008). Although Judge and Ball's (2008) questionnaire restricted respondents to three 'causes' for supporting caste endogamy (i.e. tradition, better understanding between spouses, and family support), it is possible that, in some social contexts, SC members have themselves come to accept and reproduce social representations of their groups' social inferiority vis-à-vis HCG. Crucially, this may explain the SC members' tendency to maintain social distance from, and their passive submission to, members of HCG. It is likely that these social representations are accepted and reproduced by even members of the SC due to the pervasiveness of 'casteism'. As Judge and Ball (2008, p. 49) note, 'casteism is embedded in the mind and the worldview of the people and may persist longer than the changes in the caste system'. This is coterminous with theorising within the field of identity and social representations, which suggests that pervasively shared hegemonic social representations rarely provide individuals with scope for re-construal and contestation resulting in the uncritical acceptance and reproduction of these representations (Breakwell, 2001; Jaspal \& Coyle, 2009). Thus, within the minds of individuals, stigma associated with specific caste groups seems to be justified by a system of ideas and principles. This is likely to impede major social change such as the de-stigmatisation of the SC groups.

\section{External attribution and the meaning principle}

Given the negative social representations of discrimination, individuals frequently attempt to rationalise and justify caste-based stigma. For instance, one strategy employed by the Jats (a $\mathrm{HCG})$ to justify and to rationalise the exclusion of the SC from Sikh religious contexts is to highlight the inauthenticity of the SCs' Sikh identity. It is common to refer to the tendency of many Ravidasi men (a SC) to shave their beards and to cut their hair. Evidently, there are many Sikh men of other caste groups who decide to shave and to cut their hair but who are, nonetheless, accepted and included within the Sikh community. They are usually referred to as 
'Sahajdhari' Sikhs (Shani, 2000). The particular stigmatisation of Ravidasi men suggests that it is in fact the perceived innateness of their alleged social inferiority, which impedes the HCGs' acceptance and inclusion of these caste groups even within the religious group. Social representations of discrimination are increasingly negative in modern society. Thus, individuals may feel uncomfortable manifesting overt discrimination against individuals purely on the basis of their social group membership. Thus, the meaning principle of identity may require discriminating individuals to develop intrapsychically, and to present interpersonally, explanations and justifications for their discriminatory behaviour. This imbues their discriminatory behaviour with meaning. The 'otherisation' of the SC from the religious ingroup, by declaring their alleged inauthenticity, constitutes a form of external attribution, whereby one's own discriminatory behaviour is justified by constructing the outgroup's behaviour as causal and as conducive to their 'otherisation'. This is likely to benefit the meaning principle of identity, which requires that individuals perceive 'integrity of the self-image' (Tajfel, 1969, p. 92). Indeed, individuals who habitually regard themselves as fair, egalitarian individuals must strive to ensure the integrity of this self-image, which is essential for identity, by providing a causal explanation and justification for their potentially contradictory discriminatory behaviour.

Nesbitt (1994, p. 120) argues that members of HCG may attribute the allegedly 'loose' behaviour of Valmikis (e.g. the consumption of meat and alcohol) to the perceived 'inability of the lower social orders to behave with propriety'. She makes an interesting point in observing that, while the consumption of meat and alcohol among HCG may be regarded as 'excessively modern' or 'progressive' and possibly attributed to the infiltration of British norms and values within the South Asian community, Valmikis are further stigmatised as a result of their engagement in these practices. The origins of these practices are perceived to be their allegedly innate immorality and impurity, which impede propriety and thus complete acceptance and inclusion within the religious ingroup. Social representations of the Valmikis' engagement in such practices may be rendered salient in order to fortify over-arching, hegemonic representations of their alleged inferiority (Breakwell, 2001). Thus, the representations serve a particular function for identity; this enhances the meaning principle, since it provides an accessible explanation for the discrimination directed towards members of the SC. Through the process of anchoring the representations facilitate an enhanced sense of meaning, since individuals are permitted to reinforce their worldview that caste is not arbitrary but grounded in actual 'facts' (Moscovici, 1988). Crucially, the anchoring of these social representations is likely to endow HCG members with the ability to locate significance and meaning in the caste system (Baumeister, 1991). Indeed, it has been found in empirical research that individuals will seek to make sense of the surrounding social world by attributing negative and positive characteristics of individuals to their social group membership. For instance, as discussed above, Jaspal and Cinnirella (in press) have found that gay Muslim young men may attribute their homosexuality to their upbringing in Britain due to the perceived 'normality' of homosexuality in 'British culture'. This essentially satisfies the human motivation to attribute meaning to social phenomena pertinent to one's identity. At an intergroup level, it is likely that the anchoring of social representations of the SC to allegedly 'improper' acts such as the consumption of alcohol and meat enables members of HCG to construct the ingroup as positively distinctive from the SC. Indeed, criteria are provided for self-categorisation as 'moral' and 'proper', which conveniently favour the ingroup (Jaspal \& Cinnirella, 2010a). In short, the SCs' engagement in supposedly negative, immoral social practices is explained by their caste membership. 
Many writings on caste affiliation allude to the importance of external attribution and social representational anchoring among caste group members. In Agarwal's (2004) field study of the Bedia caste (a SC), it was found that members of other caste groups tended to anchor social representations of the Bedia to representations of prostitution and sexual immorality, due to the caste group's historical engagement in prostitution. The hegemonic social representation that prostitution constitutes the 'traditional' occupation of the caste group renders them 'the lowliest of the low in general opinion' (Agarwal, 2004, p. 224). Indeed many caste groups have distanced themselves socially and psychologically from the occupations, which are traditionally associated with their groups. For instance, the Ravidasis have, in many cases, disengaged with their 'traditional' occupation of tanning, and not all Valmikis sweep up debris in the village streets. Similarly, prostitution can no longer be regarded as the primary occupation of the Bedia. However, social representations of sexual immorality and impropriety persist in those social contexts, in which the Bedia constitute a known caste group. Consequently, the perceived continued existence of sexual impropriety among the Bedia is attributed by caste outgroups to their 'traditional' occupation of engaging in prostitution. In the generally conservative society of India, the attribution of sexual immorality to caste membership may provide a socially desirable explanation with positive outcomes for the meaning principle of identity. Indeed, the search for meaning constitutes a means of dealing with psychologically challenging situations, such as the acceptance of sexual immorality within one's society. In essence, this is coterminous with the observed need for human beings to search for meaning in coping successfully with major life events such as bereavement (Golsworthy \& Coyle, 1999) and terminal illness (Taylor, 1983). Similarly, a social group can be said to search collectively for meaning in order to explicate nonnormative, stigmatised behaviour within society. The attribution of sexual immorality to a single caste group provides a necessary and convenient explanation. Accordingly, members of other castes likely regard their engagement in 'improper' sexual practices as a 'natural' consequence of their caste background.

The importance of the meaning principle of identity, in relation to caste identity, ensures that caste-based stigma persists, although this must be explained and justified by individuals and groups. For instance, Ballard (1994b) observes that contrary to the popular belief that the social processes of migration, urbanisation, commercialisation and globalisation might eventually undermine the caste system and 'blur' the hierarchical boundaries between caste groups, social representations of caste remain vividly active among many South Asians both in the Subcontinent and in the Diaspora due to the potential benefits for identity processes. Members of some SC (e.g. the Ramgarhia) have generally grown wealthy upon migration to Britain, where they have sought to use their 'traditional craft skills', coupled with the qualifications and other manual experience acquired in East Africa and Britain, in order to ascend the social hierarchy (Ballard, 1994c). However, members of HCG (e.g. the Jats) have generally responded to their social mobility by categorising the Ramgarhia as the 'nouveau riche' and by rendering salient social representations of their occupational position within rural contexts of India. Thus, the stigma associated with the SC continues to pervade everyday thinking vis-à-vis these groups, particularly among HCG.

\section{Conclusion}

The primary aim of this paper has been to provide socio-psychological insights into caste identity, which has traditionally been the domain of sociologists and anthropologists. More specifically, the functions of caste-based stigma for identity among both the SC and the HCG 
have been explored through the lens of identity process theory (IPT). Existing theoretical and empirical work on caste identifies the importance of social hierarchy, the social and spatial segregation of caste groups in accordance with social status and the historical division of labour. Moreover, it is acknowledged that social representations of caste will differ in accordance with social context. The present paper has elaborated these dimensions of caste through the lens of IPT and theorised some of the potential repercussions for identity processes, providing scope for the empirical exploration of some potentially generalisable hypotheses regarding caste identity.

In attempting to explore the functions of caste identity for the self-concept, it has been argued that IPT constitutes a fruitful theoretical point of departure. One key assumption of IPT is the agency of the individual in shaping and constructing identity, although this is subject to societal constraints, such as those imposed by social representations (Breakwell, 2010). Indeed, this appears to explain the tendency of many SC members to accept and assimilate social representations of their group's inferiority despite the ensuing potential threats to identity (Breakwell, 2001). Moreover, existing work on caste affiliation and inter-caste relations alludes to some of the ways in which the identity principles outlined by IPT may be affected. The present paper has discussed key issues in the caste literature in order to discern the potential impact for the principled operation of identity processes, which has facilitated the prediction of possible patterns of caste identification and of inter-caste relations. A key benefit associated with IPT concerns its theorisation of how individuals cope with threatened identity. Indeed, this dimension of the theory may explain and predict how caste group members will deal with social stigma and seek to ameliorate their social positions.

Caste functions as a potent social identity, since members of both the SC and the HCG frequently regard themselves, and are regarded by outgroups, primarily in terms of their caste group membership. Existing research into caste identity reveals the social stigmatisation of the SC both among the HCG and among many SC members themselves. Given the potency of caste as a social identity, individuals may be regarded as interchangeable members of their caste groups, with the result that caste group membership seems to 'provide the primary schema through which everything about them [caste group members] is understood' (Crocker et al., 1998, p. 507). Thus, negative social representations of caste groups may plausibly threaten the self-esteem principle among the SC, although the negativisation of the SC may conversely enhance the self-esteem, meaning and distinctiveness principles among the HCG. Self-esteem is enhanced through processes of downward comparison, since the comparison of one's caste group with less 'fortunate' outgroups will likely increase the sense of self-worth on the basis of one's caste group membership among the HCG. This prediction is consistent with theorising within the social identity theory tradition (Wills, 1981; Tajfel \& Turner, 1986). Moreover, the systematic positioning of both the caste ingroup and caste outgroups within the social matrix may enhance the meaning and distinctiveness principles. It is noteworthy that the sheer ubiquity of caste identity, which is facilitated by the social 'visibility' and conspicuousness of caste, may impede potentially effective strategies for coping with identity threat. For instance, the interpersonal strategy of passing, whereby one's caste group membership is concealed from others, would be unlikely to be successful (cf. Breakwell, 1986). Consequently, SC members may plausibly be said to occupy a threatening position, while the benefits for identity processes among the HCG may be regarded as stable and consistent. However, social context will undoubtedly determine the meaning and value of caste identity for individuals.

Social and spatial segregation and the maintenance of particular behavioural patterns of inter-caste interaction seem to impact identity processes among the HCG and the SC in different 
ways. The self-esteem, distinctiveness and continuity principles of the HCG members will likely be enhanced, since segregation and the perceived humility of the SC in inter-caste interactions with the HCG would be expected to facilitate a positive self-conception on the basis of one's caste membership (Gecas, 1982). Moreover, this will facilitate the perception of intergroup differentiation and a sense of temporal continuity, which is implicated in the maintenance of 'tradition'. Conversely, these demeaning social practices are unlikely to benefit the self-esteem principle among the SC, since they act as a reminder of their relatively low social status (Jaspal \& Sitaridou, 2010). Nonetheless, it has been argued that, even among the SC, the continuity principle may remain intact as a result of the maintenance of segregation and restrictions on inter-caste social interaction, since individuals will resist massive social change conducive to the restructuring of a social system to which they are acutely accustomed. Thus, despite the potential benefits for self-esteem, the continuity principle may in fact favour the maintenance of these demeaning social practices (Vignoles et al., 2002).

While social and spatial segregation may be threatening for identity among the SC, it seems to have positive implications for identity processes among the HCG. Despite the Indian government's attempts to dismantle caste-based stigma and segregation through the co-education of the HCG and the SC in state schools, segregation is maintained through the tendency of the HCG members to send their children to private schools, while categorising state schools as 'dalit' and 'harijan' schools, thereby constructing this as SC space. Indeed, caste de-segregation may be perceived as imperilling group continuity. Given that segregation may enhance distinctiveness, self-esteem and continuity, those caste ingroup members who are perceived as transgressing social norms such as caste segregation through inter-caste marriage, for instance, may be perceived as ingroup 'Black Sheep' and, thus, excluded from the ingroup (Marques, Yzerbyt, \& Leyens, 1988).

Although segregation and restrictions regarding inter-caste interactions are generally accepted by members of the SC, perceived exclusion from religious social contexts may pose dire threats to the belonging principle of identity (Vignoles et al., 2006). It is argued that the belonging principle will be threatened when individuals or groups are excluded from those social contexts, in which they would habitually expect to perceive feelings of acceptance and inclusion. Accordingly, the SC would be unlikely to experience threats to belonging as a result of the prohibition of inter-caste marriage, since there has never existed a serious social expectation among the SC that inter-caste marriage should be permissible (Judge \& Bal, 2008). Conversely, many SC members do lay claim to Hindu or Sikh religious identities and, thus, their 'otherisation' from religious institutions is expected to jeopardise their expected sense of belonging. The exclusion of the SC may benefit the continuity and self-esteem principles of identity among the HCG, given that this may constitute a logical continuation of 'otherisation' and discrimination widespread in other social contexts.

It is evident that caste-based stigma and inter-caste relations serve distinct functions for identity processes among the SC and the HCG. The empirical investigation of these functions has been omitted in the caste literature and, thus, it is hoped that future research will engage with this socio-psychological dimension of caste. The development of a satisfactory research instrument for tapping into the implications of caste for identity processes is a prerequisite to achieving this aim. The Caste Identity Scale (CIS) consists of ten items, which have been developed on the basis of previous ethnographic and cultural psychological research into caste beliefs (Mahalingam, 2003, 2007). Clearly, the role of identity processes in the construction of caste identity and in inter-caste relations is important and worthy of empirical investigation. The 
existing CIS measures essentialist beliefs regarding caste, beliefs regarding the purity of one's caste ingroup, pride in one's caste ingroup and attitudes towards inter-caste marriage. The present paper illustrates some of the ways in which these phenomena may indirectly impact the identity principles outlined in IPT. However, it is argued that the CIS may be modified in order to measure the impact for the identity principles, in a more direct manner, by including specific items measuring the principles. Although the self-esteem principle may be measured through the assessment of one's sense of pride in caste identity and the belief in one's caste group's superiority, the extent to which caste identity enhances continuity, self-efficacy, meaning and psychological coherence cannot be measured using the existing CIS. Evidently, qualitative research into caste identity will need to precede the development of a satisfactory research instrument for measuring the impact of caste identity for the principled operation of identity processes (Breakwell, 2010). Phenomenological approaches to caste may be particularly useful in tapping into the subjective meanings attached to caste identity and the perceived functions of caste for the principles outlined in IPT.

In conclusion, it is argued that the maintenance of caste-based stigma and caste segregation may be construed as beneficial for identity processes among the HCG and that, conversely, this maintains the threatening position of the SC. Given the social and political hegemony of the HCG, caste-based stigma and caste segregation are likely to persist in Indian society and social and spatial desegregation will be resisted by the HCG (e.g. Jodhka, 2004; Ram, 2004). Thus, it is important to investigate empirically the repercussions of caste for identity processes among the HCG and the SC and to debate alternative sources of identity enhancement among those caste groups which habitually rely upon discrimination and prejudice against the SC in order to enhance identity processes. It is hoped that this paper will encourage social psychologists to engage with caste identity in order to bring about positive social change both in the Subcontinent and in the Diaspora.

\section{Acknowledgements}

The author would like to thank Asha Jaspal for her guidance during the research process and Adrian Coyle for insightful and constructive comments on an earlier version of this paper. Three anonymous reviewers provided valuable insights into caste in India. The author would like to give special thanks to Professor Glynis Breakwell for her ongoing guidance regarding the use of identity process theory.

\section{References}

Agarwal, A. (2004). 'The Bedias are Rajputs': caste consciousness of a marginal community. Contributions of Indian Sociology, 38, 221-46.

Arun, C.J. (2007). From stigma to self-assertion. Contributions to Indian Sociology, 41(1), 81104.

Ballard, R. (1994a) (Ed.). Desh Pardesh: The South Asian Experience in Britain. London: C. Hurst \& Co.

Ballard, R. (1994a). Introduction: The emergence of Desh Pardesh. In R. Ballard (Ed.), Desh Pardesh: The South Asian Experience in Britain. London: C. Hurst \& Co.

Ballard, R. (1994c). Differentiation and disjunction among the Sikhs. In R. Ballard (Ed.), Desh

Pardesh: The South Asian Experience in Britain. London: C. Hurst \& Co.

Baumeister, R. F. (1991). Meanings of life. New York: Guilford Press.

Baumeister, R. F., \& Leary, M. R. (1995). The need to belong: Desire for interpersonal 
attachments as a fundamental human motivation. Psychological Bulletin, 117, 497-529.

Bourhis, R.Y., Giles, H. \& Rosenthal, D. (1981) Notes on the construction of a 'Subjective Vitality Questionnaire' for ethnolinguistic groups. Journal of Multilingual and Multicultural Development, 2, 145-155.

Breakwell, G. M. (1986). Coping with threatened identities. London: Methuen.

Breakwell, G. M. (1992). Processes of self-evaluation: Efficacy and estrangement. In G. M. Breakwell (Ed.), Social psychology of identity and the self concept (pp. 335-355). London: Academic Press/Surrey University Press.

Breakwell, G. M. (1993). Social representations and social identity. Papers on Social Representations, 2, 198-217.

Breakwell, G. M. (2001). Social representational constraints upon identity processes. In K. Deaux \& G. Philogene (Eds.), Representions of the social: Bridging theoretical traditions (pp. 271-284). Oxford: Blackwell.

Breakwell, G.M. (2010). Resisting Representations and Identity Processes. Papers on Social Representations, 6.1-6.11.

Brown, R. (2000). Social Identity Theory: past achievements, current problems and future challenges. European Journal of Social Psychology, 30, 745-77.

Chowdhry, P. (2004). Caste panchayats and the policing of marriage in Haryana: Enforcing kinship and territorial exogamy. Contributions to Indian Sociology, 38, 1-42.

Codol, J. P. (1981). Une approche cognitive du sentiment d'identité [A cognitive approach to the feeling of identity]. Social Science Information, 20, 111-136.

Crocker, J., Major, B., \& Steele, C. (1998). Social Stigma. In Gilbert, D., Fiske, S. T., \& Lindzey, G. (Eds.), The Handbook of Social Psychology (4th ed., Vol. 2, pp. 504-553). New York: McGraw Hill.

Dhanda, M. (2009). Punjabi dalit youth: social dynamics of transitions in identity. Contemporary South Asia, 17(1), 47-64.

Dovidio, J.F, Major, B. \& Crocker, J. (2000). Stigma: introduction and overview. In T.F. Heatherton, R.E. Kleck, M.R. Hebl \& J.G. Hull (eds.), The social psychology of stigma (pp. 1-30). Guilford Press: New York, NY.

Dube, L. (2001). Anthropological explorations in gender: intersecting fields. Thousand Oaks, CA: Sage.

Dumont, L. (1988). Homo Hierarchicus: The Caste System and its Implications (trans. Mark Sainsury, Louis Dumont and Basia Gulati). Delhi: Oxford University Press.

Gaertner, S.L., \& Dovidio, J.F. (2000). Reducing intergroup bias: The common ingroup identity model. Philadelphia, USA: Psychology Press.

Gayer, L. (2000) The Globalization of Identity Politics: the Sikh Experience. International Journal of Punjab Studies, 7 (2), 223-262.

Gecas, V. (1982). The self-concept. Annual Review of Sociology, 8, 1-33.

Ghurye, G.S. (1969). Caste and Race in India. Bombay: Popular Prakashan.

Giles, H., Bourhis, R.Y. \& Taylor, D.M. (1977). Toward a theory of language in ethnic group relations. In H. Giles (Ed.), Language, Ethnicity and Intergroup Relations (pp. 307-348). London: Academic Press.

Goffman, E. (1963). Stigma: notes on the management of spoiled identity. Prentice-Hall: Englewood Cliffs, NJ.

Golsworthy, R., \& Coyle, A. (1999). Spiritual beliefs and the search for meaning among older adults following partner loss. Mortality, 4, 21- 40. 
Gorringe, H. \& Rafanell, I. (2007). The embodiment of caste: oppression, protest and change. Sociology, 41(1), 97-114.

Government of India (2009). The National Commission for Backward Classes (NCBC). Available at: http://ncbc.nic.in/html/provisions.html [accessed 10 November 2010]

Gupta, D. (2004). Caste in Question: Identity or Hierarchy? Delhi: Sage.

Hogg, M. (2000). Social identity and social comparison. In Jerry M. Suls, Ladd Wheeler (Eds.). Handbook of Social Comparison: Theory and Research. New York: Plenum Publishers.

Jaspal, R. \& Cinnirella, M. (2010). The construction of ethnic identity: insights from identity process theory. Manuscript submitted for publication.

Jaspal, R. \& Cinnirella, M. (2010b). Media representations of British Muslims and hybridised threats to identity. Contemporary Islam: Dynamics of Muslim Life, 4(3), 289-310.

Jaspal, R. \& Cinnirella, M. (in press) Coping with potentially incompatible identities: accounts of religious, ethnic, and sexual identities from British Pakistani men who identify as Muslim and gay. British Journal of Social Psychology.

Jaspal, R., \& Coyle, A. (2009). Language and perceptions of identity threat. Psychology and Society, 2(2), 150-167.

Jaspal, R. \& Sitaridou, I. (2010). Coping with stigmatised linguistic identities: a synthesis of identity process theory and ethnolinguistic vitality. Paper presented at BPS Social Psychology Section Annual Conference, University of Winchester, 7th September 2010.

Jaspal, R. \& Yampolsky, M. (In press). Social representations of the Holocaust and Jewish Israeli identity construction: insights from identity process theory. Social Identities.

Jeffrey, C. (2001). 'A fist is stronger than five fingers': caste and dominance in rural north India. Transactions of the Institute of British Geographers, 26, 217-36.

Jodhka, S.S. (2004). Sikhism and the caste question: Dalits and their politics in contemporary Punjab. Contributions to Indian Sociology, 38, 165-91.

Jones, E. E., Farina, A., Hastorf, A. H.,Markus, H.,Miller, D. T., \& Scott, R. A. (1984). Social Stigma. New York: Freeman.

Judge, P.S. \& Bal, G. (2008). Understanding the paradox of changes among Dalits in Punjab. Economic and Political Weekly, October $11^{\text {th }}, 49-55$.

Kalsi, S.S. (1989). The Sikhs and caste: a study of the Sikh community in Leeds and Bradford. Unpublished doctoral dissertation, University of Leeds, UK.

Mahalingam, R. (2003). Essentialism, culture, and power: Rethinking social class. Journal of Social Issues, 59, 733-749.

Mahalingam, R. (2007) Beliefs about Chastity, Machismo, and Caste Identity: A Cultural Psychology of Gender. Sex Roles, 56, 239-249.

Mand, K. (2006). Gender, ethnicity and social relations in the narratives of elderly Sikh men and women. Ethnic and Racial Studies, 29(6), 1057-71.

Marques, J., Yzerbyt, V., \& Leyens, J.-P. (1988). The 'black sheep effect': Extremity of judgments toward ingroup members as a function of group identification. European Journal of Social Psychology, 18, 1-16.

Moscovici, S. (1988). Notes towards a description of social representations. European Journal of Social Psychology, 18, 211-250.

Nesbitt, E. (1994). Valmikis in Coventry: the revival and reconstruction of a community. In R. Ballard (ed.) Desh Pardesh. The South Asian Presence in Britain (pp. 117-41). London: Hurst and Co. 
Neuberg, S.L., Smith, D.M. \& Asher, T. (2000). Why people stigmatise: toward a biocultural framework. In T.F. Heatherton, R.E. Kleck, M.R. Hebl \& J.G. Hull (eds.), The social psychology of stigma (pp. 31-61). Guilford Press: New York, NY.

Pai, S. (2000). New social and political movements of dalits: a study of Meerut districts. Contributions to Indian Sociology, 34(2), 189-220.

Pawar, I.D. (1993). My struggle in life. Chandigarh: Author Publisher.

Philogène, G. (2000). Blacks as (Serviceable Other). Journal of Community and Applied Social Psychology, 10, 391-401.

Puri, H.K. (2003). Scheduled castes in Sikh community: a historical perspective. Economic and Political Weekly, June 28 ${ }^{\text {th }}$, 2693-2701.

Ram, R. (2004). Untouchability, Dalit consciousness and the Ad Dharm movement in Punjab. Contributions to Indian Sociology, 38(3), 323-49.

Shani, G. (2000). The construction of a Sikh national identity. South Asia Research, 20(1), 1-17.

Sharma, K L (2003). The social organisation of urban space: a case study of Chanderi - a small town in central India. Contributions to Indian Sociology, 37(3), 405-27.

Shrauger, J. S. (1975). Responses to evaluation as a function of initial self-perceptions. Psychological Bulletin, 82, 581-596.

Srinivas, M.N. (2002). The Dominant Caste in Rampura. In M. N. Srinivas (Ed.) Collected Essays (pp. 74-92). Delhi: Oxford University Press.

Tajfel, H. (1969). Cognitive aspects of prejudice. Journal of Social Issues 25, 79-97.

Tajfel, H. (1981). Human groups and social categories: studies in social psychology. Cambridge: Cambridge University Press.

Tajfel, H. (1982). Social psychology of intergroup relations. Annual Review of Psychology, 33, 1-39.

Tajfel, H., \& Turner, J.C. (1986). The social identity theory of intergroup conflict. In S. Worchel \& W. G. Austin (Eds.), Psychology of intergroup relations (pp. 7-24). Chicago: NelsonHall.

Taylor, S. E. (1983). Adjustment to threatening events: A theory of cognitive adaptation. American Psychologist, 38, 1161-1173.

The Times of India (2010). Shy of asking caste, census enumerators just guess it! The Times of India, $15^{\text {th }}$ May 2010.

Turner, J.C. (1975). Social comparison and social identity: Some prospects for intergroup behavior, European Journal of Social Psychology, 5(1), 5-34.

Turner, J. C., Hogg, M. A., Oakes, P. J., Reicher, S. D., \& Wetherell, M. S. (Eds.). (1987). Rediscovering the social group: A self-categorization theory. Oxford, United Kingdom: Blackwell.

Vignoles, V. L., Chryssochoou, X., \& Breakwell, G. M. (2000). The distinctiveness principle: Identity, meaning and the bounds of cultural relativity. Personality and Social Psychology Review, 4, 337-354.

Vignoles, V. L., Chryssochoou, X., \& Breakwell, G. M. (2002). Evaluating models of identity motivation: self-esteem is not the whole story. Self and Identity, 1, 201-218.

Vignoles, V. L., Regalia, C., Manzi, C., Golledge, J., \& Scabini, E. (2006). Beyond self-esteem: Influence of multiple motives on identity construction. Journal of Personality and Social Psychology, 90, 308-333.

Wills, T. A. (1981). Downward comparison principles in social psychology. Psychological Bulletin, 90, 245-271 